\title{
Studying the Influence of Executing Process of Knowledge Management (KM) and Information Technology (IT) on Competitive Advantage in Pharmaceutical Industry of Tehran Province
}

\author{
Mahshid Hajiabedin* \\ Department of Business Management, Firoozkooh Branch, Islamic Azad University, Firoozkooh, Iran \\ ‘Corresponding author, Email: Mahshid.abedini@yahoo.com \\ Vadood Javan Amani
}

Department of Business Management, Firoozkooh Branch, Islamic Azad University, Firoozkooh, Iran

\section{Doi:10.5901/mjss.2016.v7n2s1p533}

\section{Abstract}

This research examines Influence of Executing Process of Knowledge Management (KM) and Information Technology (IT) on Competitive Advantage in Pharmaceutical Industry of Tehran Province. The present research with respect to method of data collection is regarded as descriptive-survey and with respect to objective is regarded as applied research. In order to analyze information, it is benefit from descriptive and inferential statistics. The tool for collecting data in this study is questionnaire that its data was analyzed by using multi variable regression with fixed influence method. Results of applying Pearson and correlation test reveals having positive significant influence on knowledge management, information technology and competitive advantage. Variables of obtaining knowledge, turning knowledge, application of knowledge, protection of knowledge, information technology have direct influence on obtaining competitive advantage and the influence of application of knowledge on obtaining competitive advantage is more than other variables.

Keywords: Knowledge Management, Information Technology, Competitive Advantage.

\section{Introduction and Statement of Problem}

The world in the $20^{\text {th }}$ century is faced with significant changes in all business fields, so that at the present time through globalization, increasing competition, developing IT, attention to quality of goods and services, customer orientation, the administration of public sector all through the world is faced with serious challenges. One of the effective solutions for coping with these challenges is development of knowledge management (Asgari, 2011,). The present age is the age of explosion of knowledge information and the today's world that is based on information, the issue of knowledge management and IT (information technology) plays key role for information in society (Nonaka, 2007). In the beginning of third millennium, the issue of knowledge management is regarded as a strategic requirement for institutes, service organizations and in fact knowledge management guarantees the long term superiority for different organizations and societies and their benefit from human, intellectual and information capital (Afrazeh, 2010). Therefore the leadership duty of an organization is creating an environment for knowledge management i.e. in the present age the main challenge for managers is preparing suitable environment for growth of human mind in knowledge based organization (Bontis,1999, Drucker,1999, Gupta \& Govindarajan,2000). Thus, the most fundamental skill of managers of knowledge based organizations is "knowledge management" (Quinn,1994). The interesting point is that market distinguishes the value of knowledge and invisible factors within the process of value creation. Recently, the amount and ratio of "hidden value" is changed (Afrazeh, 2010). It is necessary to understand this reality that execution of knowledge management is necessary and knowledge management is not the solution for execution of an informing technology and only showing that at the present time we are within a knowledge based organization is not enough. In fact, knowledge management is a strategic management and it is based on supreme level of management through opportunities offered by Information Technology (IT) for utilizing complete working goals (Kalantar, 2003 Sanghani,2014). The Pharmaceutical industry plays key role on health and security of society and this issue is at center of attention by economists and policy makers. The Pharmaceutical industry in Iran during several recent decades is faced with many ups and downs; meanwhile, this industry at the present time is regarded as one of the most important strategic industries of Iran. In continuation of this 
article through examining the statement of problem, literature review, offering models for examining the influence of application of knowledge management and information technology on obtaining competitive advantage, the methodology is offered. Upon analyzing the collected data, the results of research are discussed and results of research with some recommendations are offered in the final section of research.

\section{Theoretical Fundamentals of Research}

\subsection{Knowledge Management}

This term is defined as being informed of the available knowledge in organization, creating, sharing, transferring and application of available knowledge, obtaining and saving new knowledge. These activities are performed within process of organizational learning in compliance with culture and strategy (Sallis \& Jones, 2002, McEvily \& Chakravarthy,2002).

\subsection{Acquiring Knowledge}

This term is defined as processes applied for obtaining knowledge that may be describes with words having same meaning including: obtaining, searching, producing and cooperation (Gold et al., 2001).

\subsection{Turning Knowledge}

This term is defined as processes applied for obtaining useful available knowledge (Gold et al .,2001). Japanese management researches of Nonaka and Takouchi have strong influence on discussion of knowledge management. The concept of hidden knowledge and obvious knowledge was raised by Nonaka for planning the theory of organizational learning. According to the statements of Nonaka from knowledge, the human knowledge is created and developed within social communication with implied knowledge. Nonaka and Takouchi (1995) have called this communication as "process of turning knowledge".

\subsection{Knowledge Protection}

Knowledge protection is a series of processes that protects knowledge from illegal or unsuitable application or theft (Gold et al., 2001). Maintaining knowledge consists of location of knowledge within a reservoir of knowledge that shows a type of lasting during time and this reservoir of knowledge maybe a person or an informational system. The maintained knowledge is obtained through observing experiences and activities (Sedra \& Gable, 2010).

\subsection{Knowledge Application}

Knowledge application consists of activities that shows organization has applied from knowledge. Some of the cases for application of knowledge is application of new ideas of employees at different processes and working methods of organization, improving organizational performance, making effective decisions, solving problems and attention to selling organizational knowledge(Zheng \& Mclean,2011).

\subsection{Information Technology}

Studies by N Venkatraman from university of MIT in the year 1991 revealed that organizations in late 1990's and the beginning of $20^{\text {th }}$ century are faced with a critical stage for application of technology and information technology is referred to some technologies that prepare required facilities for collecting, accumulating, processing and distributing information. This technology is based on computer and long distance communication (Sivan george,1998). Basically, computers are in charge of processing and accumulating information and prepare the ability of long distance communication and distributing information at broad level. Generally, any equipment, system or subsystems benefiting from equipment for obtaining, saving, manipulating, managing, controlling, showing, changing, transacting or receiving data or information by the executive institutes, are called Information Technology (Savery \& Lawson, 2001, Javaheri,2010). 


\subsection{Information Technology and Knowledge Management}

Knowledge management based on processing information or increasing level of organizational learning has close relationship with information technology and even in case of lack of having a specified and comprehensive definition of knowledge management, there are many synonym words. Thus, one of the effective key factors on execution of knowledge management is information technology. In order to implement knowledge management, it is required for different tools and techniques that are supported by information technology (Sharifzadeh \& Bodladi, 2008).

\subsection{Competitive Advantage}

According to the definition of Martz, competitiveness is equivalent to economic power of a qualified person or thing against its rivals in market for supplying goods, services, skills and ideas beyond the geographical borders (Zheng \& Mclean, 2011). Competitiveness at enterprise level is regarded as ability of an enterprise for designing, producing, marketing and selling products more than rivals. Christinas states that government is able to compete with Faculty of Commerce of Harvard University, if there enterprises are able to compete. Porter states that this is the enterprise that is competing in market rather than the government. Mcgahan in his research showed that $36 \%$ variance of profit making depends on inner properties of companies and their activities (Mcgahan, 2006).

\section{Research Background}

Many researches were carried out in relation to knowledge management and competitiveness; nevertheless, a few researches have dealt with relationship of these 2 issues and information technology. In a research that was carried out in the year 2006 among 25 small and medium size enterprises in America, it was found out that knowledge management is not applicable in small and medium size enterprises as large enterprises and in case of assuming that knowledge management is executed in small and medium size enterprises as large enterprises, such assumption is totally wrong. These companies are aware that they have limited resources; therefore, due to these limitations, they shall have high level of creativity (Desouza \& Awazu, 2006). Catridi in the year 2010 carried out research with title of "knowledge management as permanent competitive advantage in steel industry" and this study was performed on facilities of producing steel in South of Africa and a factory established in Brazil. This research has qualitative and quantitative approach. Researchers in order to collect the required data, benefit from questionnaire form. In quantitative approach the data are shown as numbers and digits. Findings reveal that there is significant difference between application of knowledge management as permanent competitive advantage among steel companies of Brazil and South Africa, so that the maturity age of knowledge management and organizational learning of Molad institute in Brazil is higher than South African institutes. Saedi, Mehdi, Nadalipour and Hamid (2006) in a research with title of "model of implementing knowledge management in Iran Khodro Co. based on learning and basic viewpoint toward company applying information technology" concluded that through applying 5 stages development model including: generation (emergence), improvement (development) transaction (exchange) integration, it is possible to apply knowledge management in organization with the purpose of obtaining competitive advantage and also through depending on organizational references and their improvement and qualification of organization, the knowledge management is developed based on process of learning and information technology. Piravi (2007) in a research with title of "designing knowledge management systems by using multi factor system technology for same specialty groups" believed that according to the results of research the recommended system may be complementary system for knowledge management among large organizations that facilitates transferring and sharing knowledge among employees and the system through more exact and optimum search, is able to support the relationship between same specialty groups. Mehdavi in the year 2009 carried out research about knowledge management and competition strategy of university and role on strategic factors and examined the relationship between competition strategy and knowledge management strategy by using review of theoretical basis and strategic factors. Results of this research showed that organizations that their purpose is efficiency, are mainly focused on encoding knowledge and organizations that are in search of discrimination are mainly focused on order production strategy. According to the literature review, it is stated that the following conceptual model is selected for the present research that deals with studying the influences of knowledge management and information technology for obtaining competitive advantage. In this model, the information technology and knowledge management are independent variables and competitive advantage is dependant variable. 


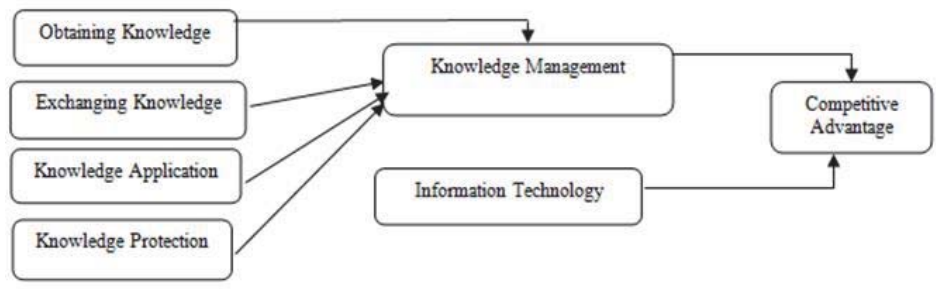

Conceptual Model Research (Nguyen, 2009)

\section{Research Hypothesis}

1- The process of obtaining knowledge has positive significant influence on obtaining competitive advantage among pharmacy industry.

2- The process of exchanging knowledge has positive significant influence on obtaining competitive advantage among pharmacy industry.

3- The process of knowledge application has positive significant influence on obtaining competitive advantage among pharmacy industry.

4- The process of knowledge protection has positive significant influence on obtaining competitive advantage among pharmacy industry.

5- The process of information technology has positive significant influence on obtaining competitive advantage among pharmacy industry.

\section{Research Methodology}

The present research with respect to data collection is regarded as descriptive-survey research and with respect to purpose is regarded as applied research. In this research, it is benefit from 2 classes of information including: elementary information and secondary information for obtaining to the purpose such as: library method (books, articles...) field method (questionnaire). In this research it is benefit from questionnaire of following research: Thi Nguyet Que Nguyen 2010. Questionnaire was distributed by having 3 sections including: competitive advantage (4 questions), information technology (4 questions), knowledge management (16 questions dealing with obtaining knowledge, exchanging knowledge, knowledge protection and knowledge application). Whereas the questionnaire was standard, the validity and reliability of questionnaire was confirmed and reliability of questionnaire by using Alpha Cronbach and being calculated by SPSS software was obtained as 0.753 . The researcher in order to determine volume sample by using Krejcie \& Morgan table, total number of 132 members were elected and the following questionnaire was distributed and completed by 130 respondents and finally was analyzed. In this research, in order to analyze data it was benefit from descriptive and inferential statistics and by using descriptive statistics, the data was collected and demographic data was classified. In order to examine the relationship between research variables and hypothesis test, it was benefit from Eviwes software and Pearson correlation test.

\section{Analysis of Findings}

Table 1: Average Test

\begin{tabular}{|l|c|c|c|c|}
\hline Variable & Average & Standard Deviation & Skewness & Kurtosis \\
\hline Obtaining knowledge & 3.65 & 0.28 & 0.21 & -0.29 \\
\hline Exchanging knowledge & 3.25 & 0.27 & 1.3 & 0.77 \\
\hline Knowledge protection & 3.35 & 0.28 & 0.38 & -0.46 \\
\hline Knowledge application & 2.21 & 0.12 & -0.2 & -0.42 \\
\hline Information technology & 3.27 & 0.36 & -0.36 & -0.19 \\
\hline Competitive advantage & 2.94 & 0.15 & -0.28 & -0.33 \\
\hline
\end{tabular}

According to the table of descriptive statistics of research variables, the highest average of research is related to the 
variable of obtaining knowledge and the lowest average is related to the variable of knowledge application and also the variable of information technology has the highest standard deviation and the variable of knowledge application has the lowest standard deviation.

\section{Normal Variable Test}

According to the output of SPSS software, it is possible to find out the normal distribution of selected variables, so that if signification level is higher than 0.05 the zero hypotheses is accepted and the claim of normal selected variable is confirmed.

Table 2: Normal Variable Test

\begin{tabular}{|l|c|c|l|}
\hline Variables & Kolmogorov-Smirnov test & Sig level & Result \\
\hline Obtaining knowledge & 1.031 & .238 & H0 hypothesis is approved \\
\hline Exchanging knowledge & .712 & .691 & H0 hypothesis is approved \\
\hline Knowledge application & .450 & .299 & H0 hypothesis is approved \\
\hline Knowledge protection & .741 & .642 & H0 hypothesis is approved \\
\hline Information technology & .777 & .582 & H0 hypothesis is approved \\
\hline
\end{tabular}

Table 3: Pearson Test

\begin{tabular}{|l|c|c|l|}
\hline Variables & Pearson Coefficient & Sig level & Result \\
\hline Obtaining knowledge & 0.721 & 0.031 & H0 hypothesis is rejected \\
\hline Exchanging knowledge & 0.784 & 0.011 & H0 hypothesis is rejected \\
\hline Knowledge application & 0.655 & .299 & H0 hypothesis is rejected \\
\hline Knowledge protection & 0.791 & 0.000 & H0 hypothesis is rejected \\
\hline Information technology & 0.798 & 0.042 & H0 hypothesis is rejected \\
\hline
\end{tabular}

Whereas correlation coefficient in the aforesaid table for the variable of obtaining knowledge is 0.721 , the variable of exchanging knowledge is 0.784 , variable of knowledge application 0.655 and variable of knowledge protection is 0.791 and information technology is 0.798 ; therefore, it is concluded that the these variables have direct significant influence on obtaining competitive advantage.

\section{Regression Significance Test}

According to the $F$ statistics for the regression, whereas the sig. level of less than 0.05 ; the regression model is significant.

\section{Co-Linear Test}

Co-linear test for the research variables is offered in the following table.

Table 4: Co-Linear Test

\begin{tabular}{|c|c|c|c|}
\hline Model & Row & Specific Amount & Index of Status \\
\hline \multirow{6}{*}{1} & 1 & 4.553 & 2.000 \\
\cline { 2 - 4 } & 2 & 1.478 & 1.345 \\
\cline { 2 - 4 } & 3 & 1.133 & 2.470 \\
\cline { 2 - 4 } & 4 & .925 & 2.226 \\
\cline { 2 - 4 } & 5 & .983 & 2.814 \\
\cline { 2 - 4 } & 6 & .945 & 2.196 \\
\hline
\end{tabular}

As it is obvious in this table, the specific amount shows the probability of domestic correlation between variables and whereas all indices are smaller than 15 , this issue shows the lack of having co-linear relationship between independent variables. 


\section{Lack of Self-Correlation Test}

Durbin-Watson statistics is offered in table that shows the self-correlation between research variables and whereas the level of this statistics in each of the tables is between 1.5 to 2.5 there is no self-correlation between research variables.

\section{Hypothesis Test and Its Results}

HO: The variables of obtaining knowledge, exchanging knowledge, knowledge application, knowledge protection and information technology do not have influence on obtaining competitive advantage. $H_{0}: \beta$

$\mathrm{H} 1$ : The variables of obtaining knowledge, exchanging knowledge, knowledge application knowledge protection and, information technology have influence on obtaining competitive advantage. $H_{0} \neq \beta$

Table 5: The results of multivariate regression

\begin{tabular}{|l|c|l|c|c|c|}
\hline Type of Variable & Symbol & Name of variable & Coefficient & T statistics & Sig level \\
\hline Dependant variable & $\mathrm{Y}$ & Obtaining competitive advantage & - & - & - \\
\hline Fixed amount & $\mathrm{a}$ & Alpha & 3.870 & 2.124 & 0.000 \\
\hline \multirow{5}{*}{ Independent variable } & & Process of obtaining knowledge & 0.454 & 1.175 & 0.033 \\
\cline { 3 - 6 } & & Process of exchanging knowledge & 0.399 & 1.395 & 0.012 \\
\cline { 3 - 6 } & & Process of knowledge application & 1.279 & 1.543 & 0.000 \\
\cline { 3 - 6 } & & Process of knowledge protection & 0.184 & 1.217 & 0.000 \\
\hline & & Information technology & 0.321 & 1.413 & 0.000 \\
\hline & & Durbin-Watson tables & 1.722 & & \\
\hline \multirow{2}{*}{ R } & & F statistics & 1.145 & & 0.000 \\
\hline R Square & & Correlation coefficient & 0.677 & & \\
\hline R adjusted Square & & Determining coefficient & 0.573 & & \\
\hline
\end{tabular}

According to this statistics, the variables of obtaining knowledge, exchanging knowledge, knowledge application, knowledge protection and information technology ( $p$-value $<5 \%)$ have significant influence on competitive advantage. According to the coefficient obtained from regression table, the variables of obtaining knowledge, exchanging knowledge, knowledge application, knowledge protection and information technology have direct influence on obtaining competitive advantage and the influence of process of knowledge application on competitive advantage is higher than other variables. According to the level of $\mathrm{F}$ statistics, the regression pattern is significant and according to the determination coefficient, these variables describe $57.3 \%$ changes of competitive advantage. Whereas level of Durbin-Watson tables is 1.5 to $2.5 \%$ it is concluded that there is no self-correlation between variables.

\section{Conclusion \& Recommendations}

According to the correlation test, the first hypothesis as having positive significant influence on process of obtaining knowledge on competitive advantage, whereas the unilateral significant level $(0.031)$ is smaller than 0.05 , the $\mathrm{HO}$ is rejected i.e. by $95 \%$ certainty it is stated that the variable of process of obtaining knowledge has direct significant influence on obtaining competitive advantage. Whereas, the correlation coefficient of this test is 0.721 it is concluded that the variable of process of obtaining knowledge has direct significant influence on competitive advantage. According to the research hypothesis, it is concluded that obtaining to required knowledge about customers, creating new knowledge from the available knowledge, obtaining to knowledge about suppliers, distributing knowledge all through the organization, obtaining knowledge related to new products about this industry and exchanging knowledge among people, leads to obtaining competitive advantage.

According to the correlation test, the second hypothesis as having positive significant influence on process of exchanging knowledge on competitive advantage, whereas the unilateral significant level $(0.021)$ is smaller than 0.05 , the $\mathrm{H} 0$ is rejected i.e. by $95 \%$ certainty it is stated that the variable of process of exchanging knowledge has direct significant influence on obtaining competitive advantage. Whereas, the correlation coefficient of this test is 0.784 it is concluded that the variable of process of exchanging knowledge has direct significant influence on competitive advantage. In compliance with results of test it is concluded that establishing the processes of exchanging knowledge are processes that are 
moving toward obtaining useful available knowledge.

According to the correlation test, the third hypothesis as having positive significant influence on process of knowledge application on competitive advantage, whereas the unilateral significant level $(0.011)$ is smaller than 0.05 , the $\mathrm{HO}$ is rejected i.e. by $95 \%$ certainty it is stated that the variable of process of knowledge application has direct significant influence on obtaining competitive advantage. Whereas, the correlation coefficient of this test is 0.655 it is concluded that the variable of process of knowledge application has direct significant influence on competitive advantage. In compliance with results of test it is concluded that if the process of sharing knowledge for manufacturing products and services and organizational activities for creating added value in organization, responding to knowledge related to customer, responding to technology related to rivals and responding to knowledge related to technology is higher, it may lead to obtaining competitive advantage.

According to the correlation test, the fourth hypothesis as having positive significant influence on process of knowledge protection on competitive advantage, whereas the unilateral significant level $(0.000)$ is smaller than 0.05 , the $\mathrm{HO}$ is rejected i.e. by $95 \%$ certainty it is stated that the variable of process of knowledge protection has direct significant influence on obtaining competitive advantage. Whereas, the correlation coefficient of this test is 0.791 it is concluded that the variable of process of knowledge protection has direct significant influence on competitive advantage. In compliance with results of test it is concluded that if the level of protection of knowledge against unsuitable application or theft of knowledge inside or outside of organization, limitation of having access to knowledge resources by technology, password and protection of implied knowledge is higher, it may lead to competitive advantage.

According to the correlation test, the fifth hypothesis as having positive significant influence on process of information technology on competitive advantage, whereas the unilateral significant level $(0.042)$ is smaller than 0.05 , the $\mathrm{HO}$ is rejected i.e. by $95 \%$ certainty it is stated that the variable of process of information technology has direct significant influence on obtaining competitive advantage. Whereas, the correlation coefficient of this test is 0.798 it is concluded that the variable of process of information technology has direct significant influence on competitive advantage. In compliance with results of test it is concluded that if technology of knowledge management is completed i.e. central processing, personal computer, Internet networks are efficient, it may act as powerful tool and having effective tools for knowledge management that enables acquiring, sharing and application of knowledge, it may lead to obtaining competitive advantage.

According to the multi-regression test between independent and dependant variable, results showed that the variables of obtaining knowledge, exchanging knowledge, knowledge application, knowledge protection against information technology (value $<5 \%$ ) has significant influence on obtaining competitive knowledge. According to the results of research in regression table, the variables of obtaining knowledge, exchanging knowledge, knowledge application, protection of knowledge and information technology have direct influence on obtaining competitive knowledge and the influence of knowledge application on obtaining competitive advantage is higher than other variables.

\section{Recommendations}

1- According to the results first subsidiary hypothesis, some recommendations are offered for obtaining knowledge for the managers of pharmacy industry in Tehran including: Creating suitable opportunities for growth of implied knowledge as reference of inner organizational knowledge, establishing growth centers at research and development unit of organization as a place for supporting from new ideas, obtaining knowledge from outer organizational database, recognizing the value of knowledge of employees, supporting from innovation, producing new ideas and benefiting from thinking engine (center) of organization, benefiting from pattern of successful organizations

2- According to the results of second subsidiary research, some recommendations are offered for exchanging knowledge for the managers of pharmacy industry as follows: Creating effective culture within process of sharing knowledge, creating suitable opportunity for exchanging knowledge, experience and skill through working teams, holding sessions of exchanging ideas through electronic means, recognizing and sharing bylaws, documents and evidences related to each position, establishing bonus system based on level of exchanging knowledge in organization, having systematic viewpoint and open opportunity for learning and transferring knowledge, creating software databank, encouraging employees for up-to-dating their knowledge through communication with persons having specific knowledge, skill and expertise, holding program for job tours of company

3- According to the results of third subsidiary research, whereas the role of knowledge application on competitive advantage is higher than other indices; therefore, it is recommended to the managers of Pharmaceutical 
industry to pay more attention to create opportunities of application of knowledge in aforesaid organizations. Some recommendations are including: establishing knowledge database, reengineering of older solutions for solving future problems, documentation of experiences due to previous projects for public application, allocating hours to hold sessions with experts and authorities of collecting new knowledge and information for improving projects, holding dialogue chamber in organization for having ask and answer sessions among coworkers.

4- According to the results of fourth subsidiary research, some recommendations are offered for exchanging knowledge for the managers of Pharmaceutical industry as follows: Establishing preventive systems, leaving employees from company, establishing on-line saving system in organization, establishing databank of organizational memory, knowledge reservoirs, registering experiences for public application at any time, place by any required person, communication with employees out of organization, management of documents including: reports and maps.

5- According to the results of fifth subsidiary research some recommendations are offered for improving information technology for the managers of Pharmaceutical industry as follows: Using up-to-date technology according to the world's recent advancements, establishing computer networks at different levels of organization, offering required training to employees for application of software, using Internet for obtaining information, establishing electronic knowledge database for persons having implied knowledge to communicate with each other without requirement for physical presence, using email, chat room, chat groups, audio and visual chat rooms, using software for knowledge producers, references of knowledge, users of knowledge available for public people.

\section{References}

Afrazeh A. (2010). A problem solving method for customer knowledge management maturity (CKMM): Case study in some Iranian oil companies. Afr. J. Bus. Manage, 4(11): 2205-2215.

Asgari Hamid, (2011),Knowledge Management and Knowledge Management Systems: Conceptual Foundations and Research Issues. MIS Quarterly, $5,-6$.

Bontis, N., Dragonetti, N.C., Jacobsen , K. \& Roos, G., (1999), "The knowledge Toolbox:: A reviiew off the Tools Available to Measure and Manage In tangible Resources"..European Management Journal Vol 17 No..4 August ,pp.391--402.

Desouza I.\& Awazu M.(2006), The knowledge Toolbox:: A reviiew off the Tools Available to Measure and Manage In tangible Resources, Information Resources Management Journal, Vol. 15 No. 2, pp. 14-21.

Drucker, Peter(1999),Management challenges 21st century,translated by Abdolreza, Rezaei Nejad,Tehran,Fara publishing.

Gold. F., Arvind Malhotra; Albert H., Segars Andrew H., (2001),Journal of Management Information Systems; Summer; 28, 4; ABI/INFORM Global pg. 162.

Gupta, A.K. and Govindarajan, V. (2000), "Knowledge management's social dimension: lessons From Nucor Steel", Sloan Management Review, Vol. 42 No. 1, pp. 77-80.

Javaheri, P. A. (2010). Explanation of the Factors Affecting Knowledge Management and Comparing Them with in Public and Private Organizations. Master's degree thesis, faculty of management, Azad University of Tehran.

Kalantar N., ( 2003), Designing of the knowledge management system by university of Technology of multifunction systems, Thesis of A.A program of Tehran university.

McEvily, S.K. and Chakravarthy, B. (2002), "The persistence of knowledge-based advantage: an empirical test for product performance and technological knowledge", Strategic Management Journal, Vol. 23, pp. 285- 305.

Mcgahan B. (2006), the impact of question structure when sharing knowledge, Electronic Journal of Knowledge Management, Vol. 1 No. 2, pp. 27-39.

Mehdavi Q.(2009), Critical Success Factors Affecting Knowledge management Adoption: A Review of the Literature. IEEE Xplore, 66-83.

Nguyen V.(2009),Critical Factors in Adopting a Knowledge Management System for Pharmaceutical Industry", Industrial Management and Data Systems, 105 (2), 164-183.

Nonaka I., Ichijo K. (2007), Knowledge Creation and Management: New Challenges for Managers, Oxford university press (Ed).

Nonaka, I \& Takeuchi, H., 1995, "the knowledge-creating company: How Japanese Companies create The Dynamics of innovation"; Oxford University Press; New York.

Piravi F.(2006), Designing of the knowledge management system by university of Technology of multifunction systems, Thesis of A.A program of Tehran university.

Quinn, J. B., (1994), Intelligent Enterorise:A Knowledge and Service Based Paradigm for industry.Free Press, New York.

Saedi,Mehdi,Nadaipour,Hamid (2006), Model of developing in placentation of knowledge management in Iran Khodro Co based on learning and source-centered glance of participation in information technology, The Second International congress of technologists management in information and development.

Sallis, E., Jones, G., (2002),"knowledge management in Education." Great Britation: Kogan Press.

Sanghani,Parag,(2014), Knowledge management implementation: holistic frame work based on Indian study, Pacific asia conference on 
information systems (PACIS),PP.1-15.

Savery D. \& Lawson O., (2001), The effects of knowledge management on innovative success-An empirical analysis of Germa firms. Research policy, 40, pp. 1453-62.

Sedra P.,\& Gable N.(2010), Overcoming knowledge management challenges during ERP implementation: the need to integrate and share different typs of knowledge. Journal of the American society for information science and technology, 58(3): $404-419$.

Sharifzadeh,H., Bodladi H. (2008), knowledge Management in administrative and services facilitating manufacturing organizations, academic center for education-research and culture, Allameh Tabatabaie University, Iran.

Sivan george, jr.(1998) time-the next source of competitive advantage, harvard business review, july-august,pp:41-51.

Zheng, W. \& Mclean, G. N. (2011). Linking organizational culture, structure, strategy, and organizational effectiveness: Mediating role of knowledge management. Journal of Business Research, 63 (7): 763-771. 